How to Cite

Hepsiba, N. (2018). The need for guidance and career counselling at secondary schooling. International Journal of Physics \&

Mathematics, 1(1), 29-36. https://doi.org/10.31295/ijpm.v1n1.41

\title{
The Need for Guidance and Career Counselling at Secondary Schooling
}

\author{
Netala Hepsiba \\ BENNIAH College of Education Burugapudi, E.G Dist. \& Andhra University, Visakhapatnam, India \\ Email: hepsibanethala@gmail.com
}

\begin{abstract}
A large number of students are going to colleges and universities without proper planning. They think of selecting a career after finishing their education. Consequently, round pegs are inserted in square holes and square pegs at round holes, resulting in wastage of human services. Due to this reason, it is, therefore, necessary to have well-organized guidance program to remove the defect. Society itself and its demand are continuously changing and becoming more and more complex and without any guidance program, it is not possible for a child to cope with the changing society. So, the program of guidance is needed for all the children in every aspect of their harmonious development.

Keywords---career counselling, guidance, secondary schooling.
\end{abstract}

\section{Introduction}

The Guidance program assumes a lot of importance for secondary schools as the Indian society is undergoing rapid change, socially as well as economically coupled with the changes in the values and lifestyle of people. School guidance is developing very rapidly in many countries around the World. As with any practice as far as the role of the counsellor is concerned in a secondary school setting, challenges and special issues are often identified, discussed and managed. At the secondary level, there is though competition among the students and this leads to frustration among students. In such a scenario the role of school guidance program is very much important to help the students in order to know their abilities, to come out of stress and problems and to lead them smoothly to pass the journey of education. Therefore it is recommended that every school should have proper guidance unit and its proper functioning should be there to help the students for their varied problems, which will help in enhances the overall quality of education, having said that, Secondary level is a period of intense physical change and formation of identity. It is also the period of intense vibrancy and energy. The ability to reason with abstractions and use logic emerges, allowing children the possibility of deep engagement with both understanding and generating knowledge beyond the here and now. The critical understanding of the self in relation to society also emerges during this period so here school guidance plays an important role to enhance the overall personality of the students. Therefore it is recommended that every school should have proper guidance unit and its proper functioning should be there to help the students for their varied problems, which will help in enhances the overall quality of education.

\section{The need of guidance and counseling}

Changing condition of the home, changing condition of Labor industry, increasing migration and population, changing in birth and death rate, increase in the amount of general education demanded. There is an urgent case for introducing and strengthening the guidance service in the secondary schools of our country to meet the varied needs of the students, administration and the educational system for the following reasons, Guidance program helps the students in their total development, making proper choices at various stages of their educational career, vocational development, to make the best possible adjustment to the situation in school as well as home etc. Thus it assists the students in making intelligent choices and adjustment in life. The ability to make such choices is not innate but like

ISSN 2632-9417

Received Jan 10, 2018 / Accepted Jun 20, 2018 / Published Jul 05, 2018 
other abilities, must be developed. It is one of the functions of secondary school to provide such opportunities for the development of such abilities. The guidance program, like any other educational program, requires careful and consistent development. Any service as comprehensive as guidance must be carefully planned if it is to meet the desired goals. When the program is well organized, there is no doubt that all involved will participate to the fullest extent. So, the teachers should see it as their own, rather than the headmaster's or guidance teacher's program. Guidance program not only helps in resolving the students' problems but also increases the chances of student's right placement, at right time in right work for their bright future.

\section{Research Methods}

Research procedure is a search for knowledge employing scientific procedures. D. SLESINGER and M. STEPHENSON in the Encyclopaedia of Education Research as "the manipulation of things, concepts or symbols for the purpose of generalizing to extend, correct or verify knowledge, whether that knowledge aids in the construction of theory or in the practice of an art."

\section{Research design}

The research design is a means of adopting that type of technique of social research which is most suitable for the research and study of the problem. "A research design is the arrangement of conditions for collection and analysis of data in a manner that aims to combine relevance to the research purpose with economy in procedure" SELLTIZ (1962); RUSSEL ACKOFF (1961), has defined it as "The process of making decisions before a situation arises in which the decisions have to be carried out. It is a process of deliberate anticipations directed towards bringing an unexpected situation under control."

Studies concerning whether variables are associated are examples of diagnostic research studies. Studies concerned with specific prediction with the narration of fact and characteristics concerning an individual, group or situation are examples of descriptive research. Most of the social research comes under this category.

\section{Research Methods}

Research methods may be understood as all those methods that are used for conduction of research. This refers to the behaviors and instruments used in selecting and constructing research techniques. This particular research incorporates both library research and field research. Therefore the methods used are:

a) Structured Questionnaire

b) Analysis of Records And Documents

\section{Sample and Variables}

The researcher used Stratified Random Sampling technique to select the samples. As it is highly suitable to measure "Career Guidance and Counselling Needs of Intermediate Students" by the random satisfied selection divides the population is strata by some characteristics and from each of these smaller homogeneous groups draw at random a predetermined number of units. The investigator planned to select schools by stratified sampling and from each college selected minimum students. These students were selected at random from 10 different colleges, which have been also at random from East Godavari District.

The colleges are stratified based on two characteristics Rural / Urban. Investigator random selected 10 colleges. Based on the first characteristics 5 Rural Colleges and 5 Urban Colleges were selected at random. The total sample consisted of 300 students of Intermediate level from different management Colleges were selected by using stratified random sampling technique.

In the present study, it was kept in mind that the sample should be representative. The sampling design was formulated to take care of this. The principle of randomness was used wherever possible. The choice of the researcher had no role in the selection of the sample.

The permission of the Directors of Intermediate colleges was sought. This is necessary to get the sanction and cooperation of the college authorities for the collection of primary data and also for getting documents and records related to Intermediate Colleges. The Director and other top personnel at the college directorate and Assistant 
Directors at different regional offices were personally contacted and their valuable suggestions and opinions were collected.

Table 1

Showing variable wise details of the students

\begin{tabular}{lllll}
\hline S. No. & Name of the Variable & Category & Number & Total \\
\hline 1 & Sex & Male & & \\
& & Female & & \\
2 & Age & 16 years & & \\
3 & & 17 years & & \\
& Management & Government & \\
& & Private & \\
\hline
\end{tabular}

A tool used for the present study

The tool used for the present study is Career Guidance and Counselling Scale developed by J.S.Grewal (1971), National Psychological Corporation.

Description of the tool

The scale measures the different aspects of the career guidance and counseling. The dimensions of scale are:

a) Educational Needs

b) Vocational Needs

c) Personal Needs

d) Health Needs

e) Leisure time activities / recreational Needs

f) Emotional Needs

g) Socio-civic Needs

h) Leadership Needs

i) Moral Needs

j) Spiritual Needs

Career Guidance and Counselling scale have a total of 70 items. These are distributed over 10 dimensions:

a) Educational Needs has 14 items

b) Vocational Needs has 14 items

c) Personal Needs has 7 items

d) Health Needs has 3 items

e) Leisure time activities/recreational Needs has 11 items

f) Emotional Needs has 7 items

g) Leadership Needs has 8 items

h) Socio-civic Needs has 3 items

i) Moral Needs has 2 items

j) Spiritual Needs has 1 item.

\section{Scoring and Interpretation}

Career Guidance and Counselling scale are self-reporting 5 point scale. The five options given on the scale are STRONGLY AGREE, AGREE, UNDECIDED, DISAGREE, STRONGLY DISAGREE. The items are so stated that if the answer is positive say 5,4,3,2, and 1 and for the negative answer of score 1,2,3,4 and 5 is to be awarded. Therefore, the higher score on a scale lowers the degree of Career Guidance and Counselling and vice versa.

Pre-test

To test the suitability of the scale and any modifications in the test are necessary. A pre-test is done on ----------students after pre-test, it is known that the test is suitable for students and is following directions easily. Hence, the investigator felt that there is no need for further modifications. 


\section{Data Collection}

The data is collected by using the questionnaire Career Guidance and Counselling Scale, from all ====== students covering the type of management, different age, and gender. The students are given instructions before filling the questionnaire. There are no right or wrong answers to the questions. The subjects have to give their response to the question in the answer sheet by giving tick-mark. After collecting the required data, it is pooled and tableted for statistical analysis.

\section{Statistical Analysis}

As the present study is of more of qualitative in nature, collected data is analyzed both qualitative and quantitative techniques. Quantitative data is analyzed with the simple statistical techniques. The investigation has been carried out by the descriptive statistical analysis, such as calculating measures of central tendency like, mean calculating measures of description like standard deviation. For testing the null hypothesis, the ' $\mathrm{t}$ ' test and analysis of variance have been used by the investigator. The ' $t$ ' test was used to test the null hypothesis when the data was co-related from matched groups. Analysis of variance with Schaffer's Post Hoc Test was used to find out the effect if any of the variables studied. The data is coded and prepared for analysis using the statistical package for research software programme.

\section{Results and Analysis}

\section{Organization of Guidance Programme at the Secondary school level}

According to Jones (1963), when the guidance services are to be recognized in secondary schools, it becomes essential that all the members of the staff properly understand that it is a team work and it can only be organized if all of them actively participate in it. First of all the senior officers of the school administration need to be provided with complete knowledge of this service and their interests cultivated in it. They need to be made acquainted with these services established in developed nations, researchers carried out its uses in human resources development, its uses in the progress of development, new developments in this field and expenditure made by such nations in it, need to be further made clear to them.

\section{Organization of the Faculty}

1) Faculty Guidance Committee: At the time of organizing guidance service in school first of all a permanent faculty committee be organized with Headmaster as the President, counsellor and all those teacher who have had some training as its member. This committee should frame the policy, fix its targets, acquaint all the staff members, parents and students with the benefit of its services, to get the expert advice for the organization of guidance services and to act upon it and to evaluate guidance service and to bring requisite changes in it. It will be better if the council is made the in-charge of the programme and it should involve all the teachers in it, in order to give proper representation on the committee.

2) The headmaster of the School: The Headmaster should have full faith in the guidance services and his philosophy of education must be clear about its relationship with guidance. He must call the meeting of the guidance committee maintain its record and have a democratic discussion. He should introduce cumulative records and train class teachers about the mode of filing proper information in it and maintain it. He should work as public relations officer and maintain good relations with students, teachers, social workers, employment officers, district level officers and Principals of colleges etc. All this will not only help him to cultivate his real interest in it but make him, the leader of the team for providing guidance facilities to the students.

3) Counselors: The counselors in secondary school environments are to concentrate on the following four tasks: (a) Organizing and making available to students comprehensive information systems necessary for educational and vocational planning and decision making. (b) Organizing and presenting classroom curricula that focus development of adolescents. (c) Helping students to assess the personal characteristics. (d) Providing remedial interventions for students needing special help. The work of counselor can be done by a teacher who has undergone at least one year's special training counselor. Counsellor is to perform all the services including: providing educational guidance and information, individual counselling, administrative 
activities and record keeping, prevention activities, providing career guidance and assistance, standardized test administration and interpretation, information dissemination, public communication and human relations, consultation activities, student development activities, group guidance and group counselling.

4) Teacher: Teacher is a friend, guide, and leader of the students. While teaching his own subject, the teacher can provide occupational information to them. He needs to be well acquainted with the different types of information, which affects his studies such as intelligence level, social interaction level, health and economic problems etc. While teaching his own subject, the teacher should provide occupational information to the students by correlating it with his subjects as and when these are an occasion for it. He is supposed to provide full co-operation to the counselors about the students.

5) School Psychologist: The school counselor is to be busy with so many multipurpose activities, so at times in each school, or in a group of schools a psychologist is appointed who conducts the needed psychological test and interprets them. The work being of highly technical native only a qualified person is appointed on it. He is always to be of great help to the counselors.

6) Health Department of School: As a rule, every large school should have a full-time doctor, a dentist, a psycholinguist, and nurse. However, till this stage is not ripe, the Government must ensure that doctors appointed in a hospital visit the schools and provide needed medical aid to the students.

7) Librarian: The librarian can be helpful to the extent that he collects the books, journal, and pamphlets on guidance, occupational information and provide necessary help to students for their use.

8) Co-operation of Parents: The social conditions in our country are such that parents need to be enlightened that children should be allowed to make their own decisions about their problems. It is better to prepare a checklist of the needed information such as what parents expect of their wards, the number of his brothers and sisters and his relationship with the types of educational facilities available at home. The parents should be encouraged to express their views in a free and frank manner. They should be dealt with psychologically.

9) Co-operation of other Organization: In order to establish guidance programme on firm footing it is essential to get the cooperation of guidance clinics, employment exchange, teacher's parent's associations, organizations of industrialists, doctors, students unions, religious and labor organizations etc.

(a) Students Welfare Services: Organizations like Teacher Parent Association, Lion's club, Rotary clubs etc. organize different types of services for the students such as medical aid, economic help etc. There can be of immense help to the school and associated to solve their problems of many students.

(b) Accommodations: In every school, a guidance corner with extensive information about occupations, shortage occupations, surplus occupations, training facilities, professional loans etc. is a must to be established.

In the same way the cumulative record will have to be maintained in good conditions as these are to be used for quite a long time. In actual practice a good many types of entries such as school achievements, achievements in co-curricular activities and important developments etc. can be made in it time and again so it will have to be suitably placed under the supervision of the counsellor for which proper accommodation is to be provided along with other requisite material such as cumulative recording material, filing cabinet etc. In this way, if the guidance is to be established on firm failings, which is becoming a necessary i.e. separate room with the above facilities will have to be made for the guidance workers to shoulder his responsibilities.

Benefits of School Guidance Programme: According to Gibson (2003), a developmental and comprehensive school guidance programme not only benefits the students but also the parents, teachers, administrators and the business community. The benefits to the various groups are as follows:

(a) Students:

1) Increase self-knowledge and how to relate effectively to others.

2) Broaden the knowledge about the changing environment.

3) Helps them reach their fullest academic potential.

4) Provides opportunities for career exploration, planning, and decision making.

5) Provides an opportunity for networking with services and thus establishes an effective support system. $\ddot{Y}$ Teaches responsible behavior.

(b) Parents:

1) Promotes an interdisciplinary team approach to address student's needs and educational goals.

2) Increases opportunities for parental involvement in the education of the child.

3) Equips parents with skills necessary to support their child.

4) Supports active partnership for student learning and career planning. 
(c) Teachers:

5) Provides data for information on student progress.

1) Promotes an interdisciplinary team approach to address student's needs and educational goals.

2) Provides an opportunity to work in collaboration with other teachers and parents.

3) Supports development of classroom management skills.

(d) Administrators:

1) Enhances the image of the school in the community and improves the general appearance of the school.

2) Allows for systematic evaluation.

3) Provides a structure which can be monitored easily.

4) Provides a proactive school guidance curriculum that addresses student's needs and enhances school climate.

(e) Business, Industry, the Labour Market:

1) Provides the potential for a well-informed workforce, with positive attitudes and the necessary skills.

2) Provides an opportunity for collaboration with teachers in preparing students for the world of work, through participation in career fairs and other career guidance activities.

3) Enhances the role of the counselor as a resource person.

4) Increases opportunities for business, industry, and labor to participate actively in the total school program.

\section{Findings}

a) There is no significant difference between male and female students with respect Educational Needs, Vocational Needs, Personal Needs, Health Needs, Leisure Time Activities/Recreational Needs, Emotional Needs, Socio-civic Needs, Leadership Needs, Moral Needs and Spiritual Needs towards career guidance and counseling needs of intermediate students.

b) There is a significant difference between 16 and 17 years students with respect Educational Needs, Vocational Needs, Personal Needs, Health Needs, Leisure Time Activities/Recreational Needs, Emotional Needs, Sociocivic Needs, Leadership Needs, Moral Needs and Spiritual Needs towards career guidance and counseling needs of intermediate students.

c) There is no significant difference between Government and Private Management Students with respect Educational Needs, Vocational Needs, Personal Needs, Health Needs, Leisure Time Activities/Recreational Needs, Emotional Needs, Socio-civic Needs, Leadership Needs, Moral Needs and Spiritual Needs towards career guidance and counseling needs of intermediate students.

d) There is no significant difference between Urban / Rural area students with respect Educational Needs, Vocational Needs, Personal Needs, Health Needs, Leisure Time Activities/Recreational Needs, Emotional Needs, Socio-civic Needs, Leadership Needs, Moral Needs and Spiritual Needs towards Career Guidance and Counselling Needs of Intermediate Students.

\section{Conclusion}

School guidance is developing very rapidly in many countries around the World. As with any practice as far as the role of the counsellor is concerned in a secondary school setting, challenges and special issues are often identified, discussed and managed. At the secondary level, there is though competition among the students to secure good marks in the exam and to select a bright future vocational option and this leads to frustration among students. In such a scenario the role of school guidance programme is very much important to help the students in order to know their abilities, to come out of stress and problems and to lead them smoothly to pass the journey of education. Therefore it is recommended that every school should have proper guidance unit and its proper functioning should be there to help the students for their varied problems, which will help in enhances the overall quality of education.

\section{Acknowledgements}

I, NETALA HEPSIBA, delightfully taking this magnificent chance to honor and heartfelt thanks to Almighty GOD for giving me birth, standing-by me and blessing me, on every footstep of my life and leading me on by His mighty 
grace. It's my immense pleasure in placing on record of my deep sense of gratitude to my beloved Father \& Mother, (NETALA LAKSHMI RAO \& SANTHA KUMARI) for supporting me on every little innocent step of mine throughout my life-so-far and for their vast encouragement to strive forward. I have immeasurable words to write about my superb Guide, who is so called Prof. Y.F.W.PRASADA RAO, Former Dean, Faculty of Education, Andhra University, VISAKHAPATNAM, for his valuable guidance, constant assistance, encouragement, constructive inspiration throughout the period of his research work and for his scholarly suggestions and guidance. I hereby express my sincere thanks to my beloved Life-partner, Younger Brothers and Sister-in-laws for their kind help and encouragement for successful completion of this course. I take this opportunity to thank all the staff and colleagues for their co-operation and support in completing the research work. 


\section{References}

Bordelois, M. I., Mustelier, J. J. B., \& Zevallos, I. V. (2018). The Career Self Evaluation in Improving the Quality of Higher Education. International Journal of Social Sciences and Humanities (IJSSH), 2(1), 84-91.

Clinton, P. X. (1992). An evaluation of high school counseling services to the success of at-risk students. (Doctoral dissertation, University of Arizona).Dissertation Abstract International, 53(5).

Dasgupta, B. (1972). Pupils Opinion On School Guidance Services In West Bengal. In M. B. Buch (Ed.).Fourth Survey of Research in Education. New Delhi: NCERT.

Dash, B. N. (2003). Guidance services in schools. New Delhi: Dominant Publishers and Distributors.

Gibson, R.L. (2003). Introduction to counseling and guidance. New Delhi: Pearson Education Publishers. 5. Huston, W. P. (1989). The guidance functions in Education. New York: Appleton Century crafts company. 6. Jones, A. J. (1963). Principles of Guidance. U.S.A.: Mcgraw Hill Book Company.

Kochhar, S.K. (2004). Educational and Vocational Guidance in secondary school levels. New Delhi: Sterling Publishers.

Macías, T. M. D., Meza, A. K. T., Garcia, B. B. B., \& Bozada, M. A. T. (2018). Characterization of Physical and Motor Disability at the Technical University of Manabí. International Research Journal of Management, IT and Social Sciences (IRJMIS), 5(2), 1-8.

Miller, W. F. (1968). Guidance principles and services. U.S.A: Charles Merrill Publisher Company.

Ministry of Human Resource and Development (1986). National Policy on Education. New Delhi: Govt. of India.

Mishra, R. (2013). A study on guidance programme in secondary schools of Vadodara city. (Unpublished M.Ed dissertation). CASE.The M. S. University of Baroda, Vadodara.

National Council of Educational Research and Training (2005). National Curriculum Framework. New Delhi: NCERT.

Srivastava, K. K. (2003). Principles of guidance and counseling. New Delhi: Kanishka Publishers.

Suryasa, I. W., Prayoga, I. G. P. A., \& Werdistira, I. W. A. (2017). An Analysis of Students' Motivation Toward English Learning As Second Language Among Students In Pritchard English Academy (PEACE). International Journal of Social Sciences and Humanities (IJSSH), 1(2), 43-50.

Tripathi, R. H. (1986). Determination of various guidance needs of the pupils of secondary and higher secondary schools. (Unpublished Ph.D. thesis). In M. B. Buch (Ed.).Fourth Survey of Research in Education. New Delhi: NCERT. 